\title{
BIODIVERSIDADE: SENTIDOS ATRIBUÍDOS E AS CONTRIBUIÇÕES DO TEMA PARA UMA EDUCAÇÃO AMBIENTAL CRÍTICA
}

\author{
Flávia Torreão Thiemann ${ }^{1}$ \\ Haydée Torres de Oliveira $^{2}$
}

\begin{abstract}
Resumo: Este artigo apresenta os resultados de nossa pesquisa, na qual buscamos compreender quais os sentidos atribuídos à biodiversidade por pesquisadoras/es e estudantes das áreas de Ciências Biológicas e afins e vislumbrar possibilidades de abordar a biodiversidade como tema de processos de educação ambiental. A pesquisa se fundamentou em uma perspectiva hermenêutica, baseando-se na interpretação dos dados obtidos com o Método Delphi. Foram criadas nove categorias emergentes de sentidos atribuídos à biodiversidade: Concretude, Simbólico, Conhecimento, Holismo, Caleidoscópio, Oculta, Ameaçada, Inclusiva e Exclusiva/Excludente. Em relação às possibilidades de trabalho, fica aberto um leque de alternativas para abordar o tema da biodiversidade em processos educativos conduzidos segundo os princípios de uma educação ambiental crítica, entendida como aquela que respeita a multiplicidade de olhares e busca a compreensão e a construção de acordos que permitam a ação em prol da diversidade de vida do planeta com base na participação e no diálogo.
\end{abstract}

Palavras-chave: Biodiversidade. Perspectiva hermenêutica. Educação ambiental crítica.

\section{BIODIVERSITY: ASSIGNED MEANINGS AND THE THEME'S CONTRIBUTIONS FOR A CRITICAL ENVIRONMENTAL EDUCATION}

Abstract: This paper presents the results of our research, in which we sought to understand the meanings assigned to biodiversity by researchers and students in the Life Sciences and similar areas, and to envision possibilities for using biodiversity as a theme in environmental education processes. The research was grounded on a hermeneutic perspective, based on the interpretation of data obtained with the Delphi Method. We created nine categories of emerging meanings assigned to biodiversity: Concreteness, Symbolic, Knowledge, Holism, Kaleidoscope, Hidden, Threatened, Inclusive, and Exclusive. Regarding work possibilities, a full range of alternatives are open to address the issue of biodiversity in educational processes conducted according to the principles of a critical environmental education, understood as one which respects the multiplicity of perspectives and seeks understanding and to build agreements based on participation and dialogue that allow for action in favor of the diversity of life on the planet.

Keywords: Biodiversity. Hermeneutic perspective. Critical environmental education.

\footnotetext{
${ }^{1}$ Mestre em Ciências (Fundação Oswaldo Cruz - FIOCRUZ/RJ); Doutoranda em Ciências - Programa de Pós- graduação em Ecologia e Recursos Naturais - Universidade Federal de São Carlos(UFSCAR), São Carlos, Brasil, flaviathiemann@yahoo.com

2 Doutora em Ciências da Engenharia Ambiental, professora associada do Depto de Ciências Ambientais, Universidade Federal de São Carlos(UFSCAR), São Carlos, Brasil, haydee@ufscar.br
} 


\section{BIODIVERSIDAD: SENTIDOS ATRIBUIDOS Y LAS CONTRIBUCIONES DEL TEMA PARA UNA EDUCACIÓN AMBIENTAL CRÍTICA}

Resumes: Este artículo presenta los resultados de nuestra investigación, en la que procuramos comprender cuáles son los sentidos atribuidos a la biodiversidad por investigadores/as y estudiantes de las áreas de Ciencias Biológicas y afines, y vislumbrar posibilidades de abordar la biodiversidad como tema de procesos de educación ambiental. La investigación se fundamentó en una perspectiva hermenéutica, basándose en la interpretación de los datos obtenidos con el Método Delphi. Se crearon nueve categorías emergentes de sentidos atribuidos a la biodiversidad: Concreción, Simbólico, Conocimiento, Holismo, Caleidoscopio, Oculta, Amenazada, Inclusiva e Exclusiva/Excluyente. Con relación a las posibilidades de trabajo, queda abierto un abanico de alternativas para abordar el tema de la biodiversidad en procesos educativos conducidos según los principios de una educación ambiental crítica, entendida como aquella que respeta la multiplicidad de miradas y procura la comprensión y la construcción de acuerdos que permitan la acción en pro de la diversidad de vida del planeta con base en la participación y en el diálogo.

Palabras clave: Biodiversidad. Perspectiva hermenéutica. Educación ambiental crítica.

\section{Introdução}

A biodiversidade está em tudo ao nosso redor, no que vestimos, comemos, em objetos de nosso cotidiano, passado e futuro. Faz-se presente como uma explosão de cores e tons, de sons e aromas. Pode estar oculta na profundeza das águas e no interior da floresta, nos jardins e praças das cidades, ou evidente no colorido das frutas e legumes na feira, de cantos e danças em festas brasileiras. É ao mesmo tempo invisível e inescapável. Os discursos sobre a biodiversidade também são múltiplos: ela é a base da vida na Terra, é essencial, e, no entanto sofre ameaça constante. O termo biodiversidade foi introduzido pelo Dr. Walter G. Rosen no contexto do Fórum Nacional em BioDiversidade (WILSON, 1988, p.VI). A Convenção da Diversidade Biológica (BRASIL, 2000) foi assinada na Conferência das Nações Unidas para o Meio Ambiente e o Desenvolvimento (Rio 92) e ao longo destes 20 anos a biodiversidade tornou-se um termo de uso corrente e hoje tanto a importância de sua proteção quanto as riquezas associadas a ela estão presentes na mídia e em inúmeros artigos científicos.

O uso desse termo biodiversidade, que se alarga para além da esfera em que foi utilizado originalmente, faz pensar em como ele é entendido pelas pessoas. A questão que guiou esta pesquisa foi compreender, por meio de um procedimento interpretativo, de interação das pesquisadoras com os textos produzidos pelas pessoas que participaram da pesquisa, os sentidos atribuídos à biodiversidade por diferentes grupos ligados à conservação da biodiversidade e educação ambiental, tais como estudantes e especialistas, pesquisadoras/es, técnicas/os e educadoras/es. Essa compreensão foi feita a partir do referencial da hermenêutica filosófica de Hans-Georg Gadamer (1900-2002). Mais do que reproduzir a opinião expressa pelas/os participantes da pesquisa, entendemos que a tarefa de uma abordagem hermenêutica de pesquisa é "entrar em diálogo com o texto" (GADAMER, 2012, p. 480) e por meio das perguntas abrir "possibilidades de sentido" (GADAMER, 2012, p. 489). Considerando, como Gadamer (2012, p. 579), que a 
"constituição da nossa experiência de mundo estruturada na linguagem está em condições de abarcar as mais diversas relações de vida", é na linguagem que vamos encontrar o meio em que as diferentes ideias sobre biodiversidade se manifestarão.

Alguns autores escrevem sobre a natureza "mal definida" de conceitos emergentes afirmando que "não há uma perspectiva ou definição única de biodiversidade ou sustentabilidade que as descreve precisamente em todas as situações e contextos" (DREYFUS; WALS; VAN WEELIE, 1999, p. 37). Não são os atributos ou dimensões da biodiversidade que não são bem definidos, mas "as abordagens é que são distintas, gerando seleções diferentes de atributos relativamente bem definidos" (DREYFUS; WALS; VAN WEELIE, 1999, p. 40), dependendo do contexto ou situação. Isso permite que a aprendizagem sobre a biodiversidade seja contextualizada e que a pluralidade de significados seja considerada e respeitada, assim como as incertezas e disputas sempre presentes na questão ambiental. A pluralidade de concepções sobre biodiversidade também é discutida por Santos (2005, p. 61), que considera que a biodiversidade é um conceito polêmico e que o "discurso sobre a biodiversidade é, de fato, um conjunto de discursos em que se cruzam diferentes conhecimentos, culturas e estratégias políticas". A diversidade de contextos em que a questão da biodiversidade pode ser abordada, longe de ser uma fraqueza, a torna relevante como tema para a educação ambiental, como Dreyfus, Wals e Van Weelie (1999, p. 37) argumentam: "biodiversidade aproxima grupos distintos da sociedade buscando uma linguagem comum para discutir questões de conservação da natureza". Saito (2013) também considera que a biodiversidade pode ser considerada um tema privilegiado para a educação ambiental.

Procedimentos metodológicos

Esta é uma pesquisa qualitativa, que, segundo Denzin e Lincoln (2006, p. 17), usa uma abordagem naturalista que busca "entender, ou interpretar, os fenômenos em termos dos significados que as pessoas a eles conferem". Trabalhamos com os paradigmas construtivista-interpretativo e crítico, este na ótica da hermenêutica crítica (KINCHELOE; MCLAREN, 2006). Ambos são compatíveis, pois operam dentro de "ontologias relativistas (múltiplas realidades construídas), de epistemologias interpretativas (o conhecedor e o conhecido interagem e influenciam-se mutuamente) e de métodos interpretativos, naturalistas" (DENZIN; LINCOLN, 2006, p. 34). A hermenêutica é entendida como postura filosófica, de cunho interpretativo. A compreensão é realizada pela interpretação das respostas oferecidas na pesquisa. Para Carvalho e Grün (2005, p. 179), a linguagem "se constitui enquanto abertura à significação, [onde] o jogo da produção de sentidos vai se dar através da dialogicidade e da interpretação". Sendo criações, os sentidos não são equivalentes a verdades, "mas sua apropriação exige a produtividade interna do sujeito" (CARVALHO, 2001, p. 26). A escolha desse referencial hermenêutico atende à nossa necessidade de explorar alternativas que possam ser acessadas em diferentes contextos de trabalho com o tema da biodiversidade, na perspectiva da educação ambiental crítica. Para Kincheloe e McLaren (2006, p. 293), pesquisadoras/es críticas/os "com frequência declaram seu partidarismo na luta por um mundo melhor". Em nosso caso, isso está refletido não apenas na busca de tratar do tema da biodiversidade dentro da esfera da ciência mas na busca de trazê-lo para o mundo. Entendemos ainda que esta pesquisa insere-se na vertente crítica da educação ambiental por seus objetivos de desvelamento de sentidos e busca de diálogo entre os conhecimentos de dimensão mais estritamente biológica, como é o conceito de biodiversidade em sua origem, e as múltiplas abordagens a que o conceito se rende em possibilidades educativas: as inter-relações, disputas, encantamento estético, valor intrínseco, a busca por causas e soluções de problemas 
relacionados à sua conservação (CARVALHO, 2008).

Em relação às considerações éticas para a condução de pesquisa educacional, foram observados cuidados relacionados ao consentimento informado de participação, considerado um conceito fundamental dos procedimentos éticos (COHEN; MANION; MORRISON, 2010, p. 52). Respeitando esses procedimentos, a participação na pesquisa foi voluntária, efetuando-se por meio de convite explicitando os termos da participação e do preenchimento de um questionário, enviado e recebido por via eletrônica. $O$ envio do questionário preenchido pelas/os convidadas/os foi entendido como aceite de participação na pesquisa.

\section{O Método Delphi - a coleta de dados e as/os participantes da pesquisa}

A coleta dos dados foi feita por meio do Método Delphi (LINSTONE; TURROF, 2002, p. 3), considerado pelos autores uma "conversação estruturada". Embora esse método, em sua origem, tenha tido como objetivo a obtenção de consenso de especialistas sobre um tema, os próprios autores dizem que há diversas maneiras de se utilizá-lo. Nossa pesquisa utilizou o que é chamado "Policy Delphi”, ou Delphi de Política (TURROF, 2002, p. 83), que tem como objetivo a geração de alternativas, e não consenso. Uma vantagem do uso desse método é que ele prescinde de encontros presenciais, o que foi fundamental em nossa pesquisa, por permitir a "conversa" entre as/os participantes, que vivem e atuam em regiões diversas do País, desde a Bacia Amazônica, na região Norte, até a do Rio Paraguai, em Santa Catarina, no Sul do Brasil. A intermediação entre as/os participantes é feita por meio das pesquisadoras, responsáveis pela aplicação e análise dos questionários. Após a coleta do primeiro questionário (DELPHI SISBIOTA ETAPA 1), as respostas foram analisadas e foi elaborado o segundo questionário (DELPHI SISBIOTA ETAPA 2), cujo objetivo principal foi permitir ao grupo posicionar-se em relação aos resultados do primeiro questionário.

Três grupos distintos foram convidados a participar da pesquisa. Para atender às premissas do Método Delphi, o critério de seleção foi a experiência prévia em biodiversidade e/ou educação ambiental, seja essa experiência no nível da graduação, pósgraduação ou profissional. Os Grupos A e B foram formados por pesquisadoras/es vinculadas/os ao projeto de pesquisa "Predadores de Topo de Cadeia Alimentar" (Edital MCT/CNPq/MEC/CAPES/FNDCT - Ação Transversal/FAPs No 47/2010 - Sistema Nacional de Pesquisa em Biodiversidade - SISBIOTA BRASIL). Esse projeto agrega 14 subprojetos com foco em predadores de topo de cadeia e os efeitos destes (e de sua ausência) na conservação da biodiversidade. Um dos subprojetos é de pesquisa em educação ambiental, do qual as autoras fazem parte. Os grupos de pesquisa estão distribuídos em vários estados brasileiros e atuam em diferentes biomas, o que confere diversidade às perspectivas apresentadas. Os questionários foram enviados às/aos 14 coordenadoras/es dos subprojetos, que puderam convidar colaboradoras/es de sua pesquisa a participar (Grupo A), e a todas/os as/os integrantes do subprojeto de pesquisa em educação ambiental - subprojeto 14 (Grupo B). O Grupo C foi composto por estudantes e/ou recém-formadas em Ciências Biológicas da Universidade Federal de São Carlos (UFSCar), em cursos de Bacharelado ou Licenciatura, que cursaram a disciplina "Educação Ambiental para a Conservação da Biodiversidade", oferecida nos anos de 2009 e 2010, e participaram em visitas guiadas a unidades do Polo Ecológico de São Carlos, SP. O polo agrega áreas em que são desenvolvidas atividades de educação ambiental nos arredores da cidade de São Carlos. As autoras foram monitora/observadora participante e professora responsável pela disciplina, e os convites foram enviados às/aos 29 estudantes 
que concluíram a disciplina. A etapa 1 contou com 33 participantes, e a etapa 2, com 24 participantes, distribuídos nos três grupos citados.

\section{Análise dos dados}

A análise de dados qualitativos pode ser feita de diversas formas. Nosso propósito foi focar de maneira progressiva os dados, começando com a visão ampla dos dados coletados e, a partir disso, em um processo contínuo de agrupar, rever e refletir sobre eles, deixar emergirem os seus aspectos mais salientes, que passaram então a orientar as análises (COHEN; MANION; MORRISON, 2010, p. 462).

Ao longo de toda a análise, a orientação da hermenêutica filosófica de que, "para compreender, é preciso que as perguntas ultrapassem o que foi dito" (GADAMER, 2012, p. 482) serviu para conduzir o processo de interpretar e compreender as respostas. A hermenêutica filosófica não determina um procedimento específico para o processo da interpretação. Segundo Kincheloe e McLaren (2006, p. 288), a produção dos textos "não segue nenhum plano detalhado ou fórmula mecânica. Assim como ocorre com qualquer forma de arte, a análise hermenêutica pode ser apreendida somente no sentido deweyano ${ }^{3}-$ executando-a". As categorias de sentido utilizadas não foram resultado de uma análise de conteúdo, foram criadas por um processo de interpretação do texto dos questionários. Assim, ao discorrerem sobre as Unidades de Conservação da Natureza e os conflitos decorrentes de sua implantação ou sobre conservação da biodiversidade e a expansão da fronteira agropecuária, as/os participantes denotavam uma preocupação com ameaças à biodiversidade, o que levou à criação da categoria Ameaçada. As demais categorias também foram criadas a partir desse olhar interpretativo.

\section{Resultados e discussão: os sentidos da biodiversidade e suas possibilidades educativas na perspectiva da educação ambiental crítica}

Nossa pesquisa foi elaborada a partir de um trabalho anterior desenvolvido sobre educação ambiental com o tema da biodiversidade (VAN WEELIE; WALS, 2002). Na pesquisa original os autores observaram diversas maneiras de se perceber a biodiversidade. Sendo assim, consideramos que o ponto inicial da análise dos dados seria compreender qual o sentido que as pessoas estavam atribuindo à biodiversidade quando falavam sobre o tema. Não fazer a pergunta de forma direta é uma escolha metodológica. As afirmativas oferecidas no questionário possibilitaram uma reflexão sobre o tema, e foi nas justificativas/motivações oferecidas para as escolhas que as formas como as pessoas percebem/apreendem a biodiversidade afloraram e deram origem à criação das categorias de sentidos atribuídos à biodiversidade.

\section{Os sentidos atribuídos à biodiversidade}

No questionário DELPHI SISBIOTA ETAPA 1 pediu-se às/aos participantes que concordassem ou discordassem de uma série de afirmativas, com a possibilidade de apresentarem a motivação para suas escolhas. As afirmativas tratavam do conceito de biodiversidade e sua relação com a educação ambiental e estão no Quadro 1.

Quadro 1. Afirmativas sobre biodiversidade e educação ambiental (adaptado de VAN WEELIE; WALS, 1999).

\footnotetext{
${ }^{3}$ Referente a John Dewey, filósofo e pedagogo que viveu nos Estados Unidos na virada do século XX.
} 


\begin{tabular}{|l|l|}
\hline & AFIRMATIVAS - “concordo plenamente” a "discordo plenamente” \\
\hline 1 & $\begin{array}{l}\text { Biodiversidade é, essencialmente, uma nova forma de se referir a tudo o que tem a ver com a } \\
\text { relação entre pessoas e natureza. }\end{array}$ \\
\hline 2 & $\begin{array}{l}\text { O poder da biodiversidade não está necessariamente em seu significado biológico ou científico, } \\
\text { mas muito mais em seu significado político, ao renovar a atenção para a conservação da natureza } \\
\text { (em nível global). }\end{array}$ \\
\hline 3 & $\begin{array}{l}\text { Educadoras e educadores ambientais precisam concordar com uma definição e significado único } \\
\text { de biodiversidade para que ela tenha qualquer potencial educativo. }\end{array}$ \\
\hline 4 & $\begin{array}{l}\text { O valor da biodiversidade para a educação ambiental está no fato de que o termo } \\
\text { "biodiversidade" tem uma variedade de significados distintos. }\end{array}$ \\
\hline 5 & É muito útil discutir se é possível afirmar que algumas espécies são mais valiosas do que outras. \\
\hline 6 & $\begin{array}{l}\text { Em educação, é importante lidar com os diferentes significados da biodiversidade, seja como } \\
\text { conceito simbólico, seja como conceito baseado em dados empíricos. }\end{array}$ \\
\hline 7 & O ensino da biodiversidade será incompleto se diversidade cultural não estiver incluída. \\
\hline 8 & $\begin{array}{l}\text { A natureza pode ser mais bem entendida quando distinguimos entre categorias como: genes, } \\
\text { espécies e ecossistemas. }\end{array}$ \\
\hline 9 & $\begin{array}{l}\text { A natureza pode ser mais bem avaliada quando distinguimos entre categorias como: genes, } \\
\text { espécies e ecossistemas. }\end{array}$ \\
\hline
\end{tabular}

Conforme descrito anteriormente, a análise das respostas foi conduzida por meio da interpretação do texto, entendida aqui como uma "conversação hermenêutica" (GADAMER, 2012, p. 502). Nessa conversação, a/o intérprete participa do sentido do texto e traz para a interpretação seus próprios pensamentos. Essa compreensão via interpretação permite que aflorem sentidos que agora são compartilhados entre autor/a e intérprete (GADAMER, 2012, p. 503; THIEMANN, 2013). Portanto, não são relacionadas aqui as respostas conforme escritas, mas já o resultado dessa conversação das pesquisadoras com o texto da pesquisa. Esses resultados foram compartilhados com o grupo na forma da segunda etapa do Delphi, para permitir a cada participante conhecer os resultados e posicionar-se com relação aos mesmos. Sendo assim, os sentidos atribuídos e temas puderam ser considerados e comentados pelo grupo.

Em nossa pesquisa usamos categorias emergentes e não predefinidas para a análise de dados, as quais foram criadas a partir da leitura criteriosa e cuidadosa dos dados obtidos. No processo de análise as respostas foram codificadas, como etapa instrumental, para permitir o retorno e confirmação da seleção das ideias e criação das categorias. Essa codificação é apresentada no corpo do texto quando há transcrição literal de trechos de texto dos questionários, colocados entre aspas. Nesse caso, está identificado o grupo a que pertence a/o autora/autor do texto (Grupo $\mathrm{A}, \mathrm{B}$ ou $\mathrm{C}$ ), seguido do número de identificação dos questionários em cada grupo, que variam de 1 a 14 , conforme o número de participantes. Sendo assim, C3 refere-se à resposta da participante 3 do Grupo C. A identificação do grupo serve aqui apenas como referência para a leitura.

As seguintes categorias de sentido foram criadas a partir da pesquisa: Concretude, Simbólico, Conbecimento, Holismo, Caleidoscópio, Oculta, Ameaçada, Inclusiva e Exclusiva/Excludente ${ }^{4}$.

A Concretude da biodiversidade quer dizer que a biodiversidade, apesar de ser um

\footnotetext{
${ }^{4} \mathrm{Na}$ pesquisa foi criada a categoria "Exclusiva", que foi reapresentada ao grupo na segunda etapa do Delphi. Porém, aqui acrescentamos o termo "Excludente", já que o termo "Exclusiva" pode ser entendido também como privativo.
} 
"conceito humano" (B1), é percebida como uma realidade concreta, palpável, de existência "independente dos seres humanos" (B1), que "sempre esteve ali" (C1). Essa biodiversidade pode ser aferida, medida, existe em uma área definida - é o "número de formas diferentes de vida em uma determinada área" (A4). Outra categoria de sentido que emergiu foi nomeada Simbólico. Aqui a biodiversidade assume seu papel de simbolizar o relacionamento ser humano-natureza. Esse "significado simbólico para a sociedade" (C2) é "revelado pelos tempos de crise ambiental" (C2). A biodiversidade adquire também o sentido Conhecimento. Em relação ao poder do conceito de biodiversidade, fica claro que o poder político que a biodiversidade tem ou pode ter advém da ciência e do conhecimento científico - "quanto mais se esclarece o tema, mais força ganha seu valor biológico" (A8). O "significado político da biodiversidade é embasado pelo significado biológico ou científico" (C6), apontando que o sentido da biodiversidade aí é de embasamento, com dados científicos, da esfera política. É por meio do conhecimento que se entende o valor da biodiversidade, e ela passa a ter poder político.

$\mathrm{Na}$ argumentação que levou à criação do sentido Conhecimento há uma atribuição de valor da biodiversidade, afirmando-se tanto o fato de que "a biodiversidade possui valor intrínseco" (A13) como a importância da "valoração econômica com relação aos bens e serviços prestados pela biodiversidade" (B5). Mas o sentido da biodiversidade para os grupos pesquisados de forma geral prescinde da atribuição de valor a espécies específicas, o que levou à criação da quarta categoria, Holismo. Os argumentos sugerem que o valor da biodiversidade está no todo, e não nas partes - deve-se "trabalhar com uma visão ecossistêmica, na qual todas as espécies são importantes" (C4). As exceções à restrição quanto à discussão de valor de espécies específicas são feitas quando "esse processo oferece subsídios para sua conservação" (C5), quando a atribuição de valor pode "ajudar a definir prioridades" (A10) de conservação e quando a discussão está centrada no próprio processo de atribuição de valor.

O sentido Caleidoscópio é depreendido do componente de diversidade da biodiversidade: diversidade de culturas, formas, sabores, receitas, sons, combinações. Aflora, por exemplo, da sugestão de temas como a "Biodiversidade e seus valores através do mundo" (C2) e "Brasil, seus biomas e sua população" (A1), bem como do uso de um brinquedo de peças que podem se encaixar em "infinitas combinações" (A1). A escolha do objeto caleidoscópio para nomear essa categoria foi feita porque, com o caleidoscópio, pequenas formas coloridas podem ser combinadas e cada combinação dá origem a uma imagem nova, que pode ser radicalmente diferente das anteriores.

O sentido de ocultamento (categoria Oculta) surge da necessidade observada de desvelamento. A biodiversidade aparece como algo que, apesar de estar ao redor, não é visto, e por isso é preciso direcionar o olhar para ela, como nos temas "Clicando a biodiversidade" (A10), que sugere o uso da fotografia para mostrar "descobertas das riquezas naturais e culturais" (A10), e "Seres vivos (e culturas) brasileiros" (B3), que sugere o foco na biodiversidade local, menos representada na mídia.

Por último, o sentido da biodiversidade como alvo de ameaças (categoria Ameaşada), que merece e precisa de proteção. Esse sentido aparece relacionado aos temas "Unidades de Conservação ${ }^{5}$ e conflitos", "Conservação da biodiversidade e expansão da fronteira agropecuária" e "(Re)Conectando a biodiversidade". A motivação para escolher trabalhar com esses temas parece denotar uma preocupação com as ameaças sofridas pela biodiversidade.

\footnotetext{
5 As Unidades de Conservação da Natureza (UCs) são regidas pelo SNUC - Sistema Nacional de Unidades de Conservação da Natureza, Lei $n^{\circ} 9.985$, de 18 de julho de 2000. Referidas no texto como Unidades de Conservação.
} 
Em relação ao ser humano, é possível perceber duas posições: o ser humano como parte da biodiversidade ou como expectador externo. Se entendermos "o ser humano como parte da biodiversidade" (B4), teremos a inclusão da diversidade cultural, pois, "considerando o homem e seu meio ambiente, devemos considerar a cultura" (C9) no sentido atribuído à biodiversidade. Porém, quando os seres humanos são percebidos como externos à natureza, sua relação com a biodiversidade é vista como interferência. O sentido da biodiversidade inclui a cultura? Quando o ser humano é considerado parte da biodiversidade, a diversidade cultural é incluída porque faz parte da diversidade humana. Mas para quem considera que o ser humano não é parte intrínseca da biodiversidade - se ela é só "diversidade de formas biológicas" e "outras diversidades não representam a biodiversidade" (A11) -, a diversidade cultural não precisa ser incluída. Disso compreendemos duas categorias de sentido, específicas para essa relação: Inclusiva e Exclusiva/Excludente.

O Quadro 2 apresenta as categorias emergentes e exemplos dos indicadores descritivos que levaram à criação das categorias, ordenadas de forma a refletir a relevância atribuída aos sentidos criados pelas/os participantes, após a realização do DELPHI SISBIOTA ETAPA 2.

Quadro 2. Categorias emergentes e indicadores descritivos que levaram à criação das categorias de sentido para a biodiversidade.

\begin{tabular}{|l|l|}
\hline $\begin{array}{l}\text { Categorias } \\
\text { emergentes }\end{array}$ & Indicadores descritivos \\
\hline Holismo & $\begin{array}{l}\text { "visão ecossistêmica... todas as espécies são importantes" (C4); "a } \\
\text { partir do momento [em] que se entende o que é biodiversidade, } \\
\text { não faz mais sentido achar que há espécies mais valiosas" (C7). }\end{array}$ \\
\hline Ameaşada & $\begin{array}{l}\text { "conservação de várias espécies vulneráveis" (A4); "fragmentação } \\
\text { de habitats e perda de espécies" (C1). }\end{array}$ \\
\hline Oculta & $\begin{array}{l}\text { "ampliar a percepção" (A10); "conhecer mais a biodiversidade } \\
\text { local" (B3). }\end{array}$ \\
\hline Inclusiva & $\begin{array}{l}\text { "entende o ser humano como parte da biodiversidade" (B4); "a } \\
\text { diversidade cultural é intrínseca à diversidade dos seres humanos" } \\
\text { (A13). }\end{array}$ \\
\hline Concretude & $\begin{array}{l}\text { "existe biodiversidade independente[mente] dos seres } \\
\text { humanos"(B1); "fato que sempre esteve ali"(C1); "número de } \\
\text { formas diferentes de vida..." (A4). }\end{array}$ \\
\hline Conhecimento & $\begin{array}{l}\text { "quanto mais se esclarece o tema, mais força ganha seu valor } \\
\text { biológico" (A8); "significado ecológico concreto de dependência... } \\
\text { auxilia no seu significado político" (B2). }\end{array}$ \\
\hline Caleidoscópio & $\begin{array}{l}\text { "formar infinitas combinações" (A1); "diversidade na nossa } \\
\text { alimentação" (B1). }\end{array}$ \\
\hline
\end{tabular}




\begin{tabular}{|l|l|}
\hline Simbólico & $\begin{array}{l}\text { "significado simbólico... de relacionamento com a natureza" (C2); } \\
\text { "conceitos..popularizados e comercializados" (C5). }\end{array}$ \\
\hline Exclusiva/Excludente & $\begin{array}{l}\text { "parâmetro responde à relação entre as pessoas e a natureza" } \\
(\mathrm{C} 4) \text {; "diversidade de formas biológicas" (A11); "as relações } \\
\text { ecológicas, os processos, ocorrem independente[mente] da } \\
\text { presença humana" (B1). }\end{array}$ \\
\hline
\end{tabular}

Fonte: Thiemann (2013).

O processo de interpretação das respostas e criação das categorias, que foram depois referendadas pelos grupos participantes, mostra alguns pontos que vale ressaltar. As categorias não são excludentes entre si. Os mesmos trechos poderiam ser utilizados para justificar a criação de mais de uma delas. Esse processo de classificação de texto em categorias originais ou já existentes não significa que estas sejam monolíticas, ou estáveis, como já demonstraram, por exemplo, Iared et al. (2011). No entanto, as categorias são uma forma de organizar e apresentar os dados e colocar em relevo os aspectos que foram considerados mais importantes nas respostas.

A categoria Holismo, criada como as demais em função da pesquisa, encontra ressonância na literatura. Sua descrição a torna muito semelhante ao que Oksanen (1997, p. 544) denomina "holismo ecocêntrico", no qual a ênfase está no todo: espécies, ecossistemas, a biosfera e os processos que mantêm a vida. A categoria Exclusiva/Excludente, que reflete a separação ser humano-natureza, foi a que teve menos ressonância com o grupo, provavelmente em contraposição à visão holística, que foi referendada por 19 de 24 participantes do DELPHI SISBIOTA ETAPA 2, o que parece corroborar a visão de Grün (2005) sobre a prevalência do enfoque holístico em educação ambiental.

\section{Temas oferecidos pelo grupo para trabalhar com biodiversidade em processos educativos na perspectiva da educação ambiental crítica}

No questionário inicial (DELPHI SISBIOTA ETAPA 1) foram apresentados cinco temas que poderiam servir como estímulo para aprender e motivar-se a agir para a conservação da biodiversidade: Biodiversidade no seu prato; Biodiversidade em trilhas da natureza; Natureza como vizinha: biodiversidade em áreas urbanas e proximidades; Conservação da biodiversidade e expansão da fronteira agropecuária; Unidades de Conservação e conflitos. Além de selecionar temas entre os sugeridos, as/os participantes acrescentaram outros dezesseis temas originais como alternativas para trabalhar com o conceito de biodiversidade, somando ao todo 21 temas (THIEMANN, 2013).

Todos esses temas (originais ou sugeridos) foram usados na construção do Quadro 3 , que apresenta seis possibilidades e sugestões de atividades educativas, criadas a partir dos temas, para trabalhar com biodiversidade em processos educativos guiados por uma perspectiva crítica de educação ambiental. Novamente essas possibilidades são fruto de um esforço de interpretação da pesquisadora em diálogo com as motivações apresentadas pelas/os participantes. É importante ressaltar ainda que, como em relação às categorias, as possibilidades relacionadas poderiam abrigar outros temas e são apenas uma das propostas possíveis de organização dos resultados.

Quadro 3. Possibilidades de abordagem do tema da biodiversidade em processos educativos. 


\begin{tabular}{|c|c|}
\hline Possibilidades de trabalho emergentes & Sugestões de atividades educativas propostas \\
\hline 1.Experimentar a biodiversidade & $\begin{array}{l}\text { Sentido de experiência, como na sugestão de usar } \\
\text { peças idênticas (LEGO) para montar combinações e } \\
\text { produtos finais diversos; relações entre } \\
\text { biodiversidade e alimentação; trilhas da natureza. }\end{array}$ \\
\hline 2.“Abrir os olhos” para a biodiversidade & $\begin{array}{l}\text { Uso da fotografia; aves aquáticas e áreas alagadiças; } \\
\text { canções; teatro, histórias; confecções; ênfase na } \\
\text { biodiversidade brasileira; folclore, festas tradicionais. }\end{array}$ \\
\hline 3.Exercitar diálogo/debates & $\begin{array}{l}\text { Discutir conflitos em UCs; exercício crítico; } \\
\text { desvelamento das "engrenagens"; outros fazeres, } \\
\text { como a agroecologia; expansão agropecuária e } \\
\text { biodiversidade. }\end{array}$ \\
\hline \begin{tabular}{lcccc} 
4.Perceber a & \multicolumn{2}{c}{ importância } & da \\
biodiversidade & e & os limites & da \\
interferência humana & & &
\end{tabular} & $\begin{array}{l}\text { Observar a presença de elementos da biodiversidade } \\
\text { no cotidiano; pensamento sistêmico; preservação das } \\
\text { florestas; conhecer a diversidade. }\end{array}$ \\
\hline 5.Biodiversidade no próprio território & $\begin{array}{l}\text { Trilhas urbanas; processos históricos de ocupação do } \\
\text { território. }\end{array}$ \\
\hline 6.Superação da fragmentação do ensino & Visão holística da natureza. \\
\hline
\end{tabular}

Fonte: Thiemann (2013).

A composição das possibilidades de trabalho mostra que as diversas sugestões de atividades trazem abordagens criativas para o tema, nas quais são privilegiados conteúdos científicos, como os processos envolvidos na origem da biodiversidade (sua origem na combinação infinita de "blocos", como genes, aqui exemplificados pelo brinquedo LEGO), mas sempre na forma de um exercício crítico que busca debater e entender os processos que estão ameaçando sua conservação, como na questão dos conflitos em Unidades de Conservação da Natureza, considerando-se valores sensoriais, e não apenas cognitivos (por exemplo, em atividades que envolvem manifestações artísticas). Como as categorias de sentido apresentadas na seção 3.1 foram criadas em parte com base nas motivações apresentadas para a escolha/elaboração dos temas, indico aqui as categorias relacionadas, sempre que for pertinente.

As possibilidades agrupadas como Experimentar a biodiversidade são aquelas em que é possível ter uma experiência sensorial em relação à biodiversidade e estão relacionadas ainda à categoria de sentido Caleidoscópio. Em relação ao brinquedo LEGO, a ideia é ter uma experiência pessoal de como a biodiversidade é formada, a partir de infinitas combinações de um número limitado de peças iguais. Aí estão também as sugestões de trabalho com a alimentação, em que a proposta é observar a origem dos alimentos, tanto em sua diversidade quanto em termos da presença de produtos da biodiversidade brasileira na alimentação cotidiana (ou sua ausência), e aspectos relacionados a formas alternativas de sua produção. Por fim, foi incluída a atividade "Biodiversidade em trilhas da natureza", que permite experimentar as sensações propiciadas pelo contato direto e a aprendizagem sobre biodiversidade no ambiente.

Em “Abrir os olhos” para a biodiversidade estão as sugestões relacionadas à categoria de sentido Oculta, uma vez que trazem uma série de ideias para que se perceba biodiversidade, seja por meio de fotografia, de canções e outras manifestações culturais, do folclore, do próprio uso da biodiversidade brasileira na confecção de artesanato, com enfoque na cultura e biodiversidade brasileiras. Essa ênfase é justificada em contraposição à presença dominante, na mídia e nas publicações (principalmente voltadas ao público 
infantil) de forma geral, de animais que não são de nossa fauna. Nesse grupo foram incluídas as sugestões relacionadas à observação de aves.

Agrupadas em Exercitar diálogo/debates estão as propostas que também deram origem à categoria Ameaçada, criada a partir das motivações apresentadas por várias/os participantes. Aí a ideia é dialogar sobre as questões relacionadas à criação de áreas protegidas e Unidades de Conservação da Natureza, a sua importância, os problemas que costumam surgir quando há populações residentes no interior ou entorno dessas áreas e a expansão da fronteira agropecuária, que pode ser um motor de perda de biodiversidade. Estão incluídos os debates sobre a produção agrícola, as alternativas da agroecologia e dos cultivos orgânicos, além da polêmica em torno da revisão do Código Florestal, ocorrida ao longo de 2012, que culminou com uma nova legislação mais leniente em questões de preservação ambiental ${ }^{6}$.

Em relação às sugestões para se Perceber a importância da biodiversidade e os limites da interferência humana, a intenção é a observação da biodiversidade no dia a dia, reconhecendo sua importância para a vida humana, mostrando que quase tudo que usamos como roupas, alimentos, produtos tem sua origem na biodiversidade, "discutir a importância da biodiversidade para a preservação das florestas" (B8), introduzir o pensamento sistêmico, que se aproxima da categoria Holismo, e finalmente evidenciar que existe um limite para a interferência humana. Outra categoria que se aproxima desse tema é Conhecimento, em relação à atribuição de valor à biodiversidade pelo reconhecimento de sua importância para o ser humano.

O reconhecimento da Biodiversidade no próprio território, o tema seguinte, pode ser feito por meio de trilhas dentro da própria cidade e proximidades, como em áreas verdes e praças, aproveitando para discutir o próprio processo de ocupação urbana e sua história, ou por meio do enfoque nos biomas e na biodiversidade local, inclusive colocando em pauta a discussão de valores econômicos, sociais e culturais. Esse tema pode ser associado ainda à categoria de sentido Oculta, por ter também um caráter de desvelamento da biodiversidade no ambiente urbano e território.

O tema da Superação da fragmentação do ensino é proposto em função da ausência, percebida por uma participante, de uma visão holística que explore ao mesmo tempo as funções e a importância de cada componente da natureza e suas inter-relações, o que poderia auxiliar inclusive a debater questões como consumo, exploração, respeito, com ênfase no valor intrínseco de cada ser vivo e seu direito à existência. Esse tema está relacionado ainda à categoria Holismo. Incluída nesse tema está a sugestão do estudo da Terra e biodiversidade, que propõe um enfoque nas relações entre os fenômenos físicos e processos de organismos vivos.

\section{Considerações sobre os temas propostos}

O caráter sensorial do trabalho com biodiversidade e a diversidade de abordagens que privilegiem aspectos da cultura, flora e fauna brasileiras estiveram presentes em ambas as partes da pesquisa. Essa ênfase na biodiversidade brasileira na educação é defendida por John (2006), que vincula a apropriação cultural da nossa biodiversidade a uma exposição maior da população aos elementos que são parte dela. Em vez de privilegiar animais de outros continentes, é fundamental que sejam divulgadas as nossas espécies nativas, bem como as tradições culturais e populações tradicionais com conhecimentos sobre essas

\footnotetext{
${ }^{6}$ Foram promulgadas as leis: $\mathrm{n}^{\circ} 12.651$, de 25 de maio de 2012, e no 12.727 , de 17 de outubro de 2012, que alteram e revogam outras leis e decretos, entre estes a Lei $n^{\circ} 4.771$, de 15 de setembro de 1965, a lei do Código Florestal.
} 
espécies.

Os conflitos relacionados à conservação da biodiversidade em áreas protegidas e em seu entorno e a importância da educação ambiental para o tema já foram afirmados em diversos trabalhos, como em Carvalho, Grün e Avanzi (2009), que testemunharam o descontentamento de moradores com as medidas de conservação adotadas no Vale do Ribeira. As áreas protegidas, na forma de matas ciliares e reservas de mata nativa, são ponto focal na discussão sobre conservação de biodiversidade e expansão da fronteira agrícola. A monocultura e a consequente perda de biodiversidade podem ser discutidas em contraponto a alternativas como a agroecologia, que prioriza a diversidade no plantio e o cultivo orgânico. $\mathrm{O}$ respeito à natureza e aos seus limites, tema proposto por uma das participantes (Biodiversidade no Limite - C10), é situado por Carvalho (2001, p. 61) na esfera da ética ambiental, segundo a qual "o respeito aos processos vitais e aos limites da capacidade de regeneração e suporte da natureza" deveria balizar as decisões sociais e reorientar "os estilos de vida e hábitos coletivos e individuais".

A biodiversidade presente no próprio território pode incluir a questão da arborização urbana, as microbacias hidrográficas e os processos históricos de ocupação do município, que podem ser relembrados por meio das memórias das/os habitantes, constituindo-se em atividades de educação ambiental. A conservação da biodiversidade em áreas urbanas é o foco do artigo de Dearborn e Kark (2009), que veem nas áreas urbanas a oportunidade de trabalhar a educação ambiental com um público que não tem condições (ou motivação) para se locomover para áreas não urbanas, onde a educação ambiental baseada em vivências na natureza é tradicionalmente realizada.

Em relação à preocupação com a fragmentação do ensino, um dos temas sugeridos, Oliveira (2012, p. 181) defende que "a abordagem transdisciplinar busca a superação dos problemas resultantes da fragmentação do conhecimento (grifo da autora), inserida num movimento de crítica à ciência moderna". Uma possibilidade apontada pela autora é o trabalho com projetos, uma metodologia que permite a elaboração e reflexão sobre que projetos de futuro queremos começar a construir no presente (OLIVEIRA, 2012, p. 181). González-Gaudiano (2005, p. 220) relaciona às pedagogias críticas essa intenção de desestruturação das disciplinas convencionais e a produção de conhecimentos interdisciplinares, que estão mais bem posicionados para lidar com a complexidade do mundo real. Navarro-Perez e Tidball (2012) reconhecem na biodiversidade um tema que pode auxiliar a compreender a complexidade da questão ambiental.

\section{Considerações finais}

A pesquisa aponta para as seguintes reflexões:

1. A biodiversidade é percebida de formas diferentes pelas pessoas, e por isso é objeto de disputa, pois valores diferentes são ligados a ela. Torna-se essencial dialogar sobre esses valores e sobre que concepções/visões de mundo eles estão alicerçados. A hermenêutica crítica pode auxiliar nesse processo, já que ajuda a desvelar as estruturas subliminares. Uma vez que os sentidos atribuídos foram fruto da interação da pesquisadora com os textos produzidos pelas pessoas que participaram da pesquisa, por meio da interpretação do texto escrito das respostas, ao mudarem as pessoas, novos sentidos podem ser percebidos, fazendo com que este possa ser um exercício conduzido no âmbito dos processos educativos.

2. São possíveis diversas abordagens para se trabalhar com a biodiversidade: os temas apresentados podem ser utilizados em diferentes interações educativas, sejam elas no âmbito da escola ou no trabalho com comunidades, sempre pautados pelo diálogo. 
3. As ameaças à conservação da biodiversidade são múltiplas, e o fato de o grupo participante estar ligado a projetos de pesquisa e conservação em diferentes biomas ajuda a colocar isso em relevo. A expansão da fronteira agropecuária e o crescente processo de urbanização aparecem como duas das principais ameaças, e há temas propostos que podem ajudar a abordar essas questões.

4. Em relação à questão ambiental, embora obviamente esta não possa prescindir de dados científicos, não se move apenas em função destes. De acordo com a Política Nacional de Educação Ambiental (BRASIL, 1999), deve ser considerada a "interdependência entre o meio natural, o sócio-econômico [sic] e o cultural", conforme foi apontado nesta pesquisa. A esfera econômica parece ser sempre a decisiva e a educação ambiental precisa vir a ser componente estrutural das decisões, e não ser encarada como instrumento. As decisões são tomadas em clima de incerteza.

5. Em relação aos referenciais escolhidos para a pesquisa, o Delphi foi considerado um elemento valioso por permitir a realização do trabalho mesmo com a restrição quanto a encontros presencias. Essa opção, feita conscientemente pela pesquisadora, foi de cunho metodológico e restringiu a comunicação direta com as pessoas que participaram da pesquisa. $\mathrm{O}$ aprofundamento dessa comunicação, realizada até agora por meio das etapas sequenciais do Delphi, poderá ser objeto de novas investigações.

A opção por apresentar os resultados desta pesquisa como um conjunto de alternativas, e não de regras, respeita nossa compreensão de que a aprendizagem sobre a biodiversidade na ótica da educação ambiental crítica deve estar vinculada ao contexto das/dos participantes. Kincheloe e McLaren (2006, p. 290) se referem ao pensamento de Gadamer, que, ao afirmar em "Verdade e Método" que toda interpretação é situada historicamente, mostrou que "as estruturas sociais de referência influenciam as questões dos pesquisadores, as quais, por sua vez, influenciam a natureza da própria interpretação". Se toda interpretação é situada, ao mudarem as condições histórico-culturais da intérprete, também mudará a interpretação do texto, que então não pode ser considerado portador de uma verdade única, imutável. $O$ próprio ponto de vista de quem interpreta, suas preconcepções, entram em diálogo com o texto e ajudam a produzir o seu sentido. Ficam aqui, portanto, ideias, sugestões, possibilidades a serem exploradas.

\section{Referências}

BRASIL. Lei n $n^{\circ} 9.795$, de 27 de abril de 1999. Dispõe sobre a educação ambiental, institui a Política Nacional de Educação Ambiental e dá outras providências. Disponível em: < http://www.planalto.gov.br/ccivil 03/leis/19795.htm>. Acesso em: 25 jul. 2013.

Ministério do Meio Ambiente. Secretaria de Biodiversidade e Florestas. Convenção sobre Diversidade Biológica - CDB. Brasília - DF, 2000. 30 p.

CARVALHO, Isabel Cristina de Moura. A invenção do sujeito ecológico: sentidos e trajetórias em educação ambiental. 2001. 349 p. Tese (Doutorado em Educação) - Faculdade de Educação. Universidade Federal do Rio Grande do Sul, Porto Alegre, 2001.

Educação ambiental: a formação do sujeito ecológico. 3. ed. São Paulo: Cortez, 2008. 256 p. (Coleção Docência em Formação; Série Problemáticas Transversais).

CARVALHO, Isabel Cristina de Moura; GRÜN, Mauro. Hermenêutica e educação ambiental: o educador como intérprete. In: FERRARO JÚNIOR, L.A. Encontros e caminhos: 
formação de educadoras(es) ambientais e coletivos educadores. Brasília: Ministério do Meio Ambiente. Diretoria de Educação Ambiental, 2005. p. 177-187.

CARVALHO, Isabel Cristina de Moura; GRÜN, Mauro; AVANZI, Maria Rita. Paisagens da compreensão: contribuições da hermenêutica e da fenomenologia para uma epistemologia da educação ambiental. Cad. Cedes, Campinas, v. 29, n. 77, p. 99-115, jan./abr. 2009.

COHEN, Louis; MANION, Lawrence; MORRISON, Keith. Research methods in education. 6. ed. London: Routledge, 2010. 638 p.

DEARBORN, Donald C.; KARK, Salit. Motivations for conserving urban biodiversity. Conservation Biology, v. 24, n. 2, p. 432-440, 2009.

DENZIN, Norman K.; LINCOLN, Yvonna S. O planejamento da pesquisa qualitativa: teorias e abordagens. Porto Alegre: Artmed, 2006. 432 p.

DREYFUS, Amos; WALS, Arjen E. J.; VAN WEELIE, Daan. Biodiversity as a theme for environmental education. In: WALS, Arjen E. J. (Org.). Environmental education and biodiversity. Wageningen: National Reference Centre for Nature Management, 1999. ICKreport n. 36. p. 35-48.

GADAMER, Hans-Georg. Verdade e método. 12. ed. Petrópolis, RJ: Vozes; Bragança Paulista: Editora Universitária São Francisco, 2012. 631 p. (Coleção Pensamento Humano).

GONZÁLEZ-GAUDIANO, Edgar. Educação ambiental. Lisboa: Instituto Piaget, 2005. 258 p. (Coleção Horizontes Pedagógicos).

GRÜN, Mauro. O conceito de holismo em ética ambiental e em educação ambiental. In: SATO, Michèle; CARVALHO, Isabel Cristina de Moura (Org.). Educação ambiental pesquisa e desafios. Porto Alegre: Ed. Artmed, 2005. p. 45-50.

IARED, Valéria Ghisloti et al. Coexistência de diferentes tendências em análises de concepções de educação ambiental. Rev. eletrônica Mestr. Educ. Ambient., v. 27, jul./dez. 2011. Disponível em: <www.remea.furg.br/edicoes/vol27/art16v27.pdf.> Acesso em: 03 ago. 2012.

JOHN, Liana. Biodiversidade também é uma questão de educação. In: BENSUSAN, Nurit et al (Org.). Biodiversidade: para comer, vestir ou passar no cabelo? Para mudar o mundo! São Paulo: Peirópilis, 2006. p. 397-406.

KINCHELOE, Joe L.; MCLAREN, Peter. Repensando a teoria crítica e a pesquisa qualitativa. In: DENZIN, Norman K.; LINCOLN, Yvonna S. O planejamento da pesquisa qualitativa: teorias e abordagens. Porto Alegre: Artmed, 2006. p. 282-313. 
LINSTONE, Harold A.; TURROF, Murray. The Delphi Method-Techniques and Applications. Ed. Murray Turoff and Harold A. Linstone, 2002. 616 p. Available from:

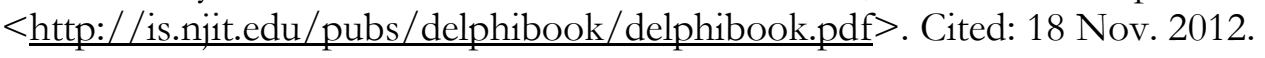

NAVARRO-PEREZ, Moramay; TIDBALL, Keith G. 2012. Challenges of Biodiversity Education:

a review of Education Strategies for Biodiversity Education. Int. Electr. J. of Environ. Edu., 2: 13-30. Available from:

<http://www.iejeegreen.com/index.php/iejeegreen/article/view/42/26 > . Cited: $25 \mathrm{Jul}$. 2013.

OKSANEN, Markku. The moral value of biodiversity. Ambio, v. 26, n. 8, p. 541-545, 1997.

OLIVEIRA, Haydée Torres de. Por que abordagens participativas e transdisciplinares na práxis da educação ambiental? In: MATHEUS, Carlos Eduardo; MORAES, America Jacintha (Org.). Educação ambiental: momentos de reflexão. São Carlos: RiMa, 2012. p. 181184.

SAITO, Carlos Hiroo. Environmental Education and Biodiversity concern: beyond the ecological literacy. American Journal of Agricultural and Biological Sciences, v. 8, n. 1, p. 12-27, 2013.

SANTOS, Boaventura de Sousa (Org.). Semear outras soluções: os caminhos da biodiversidade e dos conhecimentos rivais. Rio de Janeiro: Civilização Brasileira, 2005. 501 p. (Reinventar a emancipação social: para novos manifestos, v. 4).

THIEMANN, Flávia Torreão C. S. Biodiversidade como tema para a educaşão ambiental: contextos urbanos, sentidos atribuídos e possibilidades na perspectiva de uma educação ambiental crítica. 159 p. 2013. Tese (Doutorado em Ciências) - Universidade Federal de São Carlos, São Carlos, 2013.

TURROF, Murray. The Policy Delphi. In: LINSTONE, Harold A.; TURROF, Murray. The Delphi Method-Techniques and Applications. Ed. Murray Turoff and Harold A. Linstone, 2002. p. 80-96. Available from: < http://is.njit.edu/pubs/delphibook/delphibook.pdf $>$. Cited: 18 Nov. 2012.

VAN WEELIE, Daan; WALS, Arjen E. J. Making biodiversity meaningful through environmental education. International Journal of Science Education, v. 24, n. 11, p. 1143-1156, 2002.

WILSON, Edward O. Biodiversity. Washington, D.C.: National Academy Press, 1988. 521

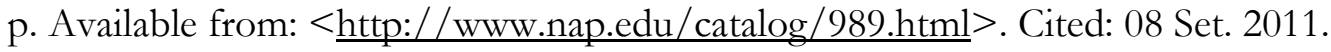

Artigo recebido em 01/07/2013

Artigo aprovado em 05/06/2013 